\title{
Bracken fern (Pteridium aquilinum (L.) Kuhn) overgrowth on dry Alpine grassland impedes Red List Orthoptera but supports local orthopteran beta diversity
}

\author{
Jürg Schlegel ${ }^{1} \cdot$ Matthias Riesen $^{1}$
}

Received: 2 January 2021 / Accepted: 8 June 2021 / Published online: 14 June 2021

(c) The Author(s) 2021

\begin{abstract}
The native bracken fern (Pteridium aquilinum (L.) Kuhn) has become increasingly invasive in abandoned or undergrazed Alpine grasslands. Bracken stands are generally assumed to be poor in species, but there is still very little information about the impact on the fauna. We recorded Orthoptera communities of 24 sample plots with varying bracken cover. Compared to plots with only sparse or medium bracken cover, species richness was highly significantly lower in densely overgrown plots, while the former two did not differ markedly. Multivariate ordination analyses revealed gradients with unequal orthopteran communities, showing distinct patterns of bracken cover clustering. Based on indicator values, 13 of 23 Orthoptera species turned out to be significantly or marginally significantly associated with a single bracken cover stratum or a combination of two strata, whereby all nine Red List species were primarily restricted to sparse or medium bracken cover. However, some generalist species were found to favor denser bracken stands, such as Tettigonia viridissima, contributing to the local Orthoptera beta diversity. Our data suggest that ongoing rotational sheep grazing with temporary paddocks is regarded as the most preferable management system. However, selected parts of the study area, which have only sparse vegetation and no pressure of bracken or scrub overgrowth, are recommended to be alternately left ungrazed for a few years to allow for the coexistence of different successional stages. Low-intensity bracken control measures, situationally by mowing or uprooting, are considered appropriate and should be pursued.

Implications for insect conservation Even though most specialized and rare Orthoptera species in Western Europe tend to prefer sparsely vegetated areas, subareas with medium to even dense vegetation cover might promote certain generalist species, leading to a higher local species richness.
\end{abstract}

Keywords Biodiversity $\cdot$ Conservation biology $\cdot$ Grasshoppers $\cdot$ Sheep pastures $\cdot$ Succession $\cdot$ Switzerland

\section{Introduction}

Infestation with bracken fern species (Pteridium sp.) on abandoned or poorly used grasslands has become an increasing problem in many parts of the world (Thomson and Smith 1990; Pakeman and Marrs 1992). Pteridium aquilinum (L.) Kuhn, the northern hemisphere bracken species (Der et al. 2009), is considered one of the most successful invasive plant species (Marrs and Watt 2006). In Switzerland, this native

Jürg Schlegel

juerg.schlegel@zhaw.ch

1 Institute of Natural Resource Sciences (IUNR), Zurich University of Applied Sciences ZHAW, 8820 Wädenswil, Switzerland species has spread vigorously since about 1980 (Widmer et al. 2018), mainly along forest edges, on fallow land and in poorly grazed areas (Frei et al. 2019). Bracken tends to form dense and uniform stands with low feeding value for grazing vertebrates (Birch et al. 2000) and toxicity in livestock has been repeatedly reported (Pakeman et al. 2002). Bracken has evolved a mechanism of toxin release by allelopathy which allows the fern to exert its dominance most effectively in each habitat in which it grows (Gliessman 1976; Dolling et al. 1994). High bracken density also threatens local plant species diversity due to the shading and overgrowth of vascular plants (Marrs et al. 1995; Widmer et al. 2018). As plant diversity is considered a major determinant of overall biodiversity (Hunter and Price 1992), the species richness of phytophagous insects, such as many Orthoptera, is likely to decline due to bracken overgrowth and the resulting simplification of vegetation 
(Lawton and Schroder 1977; Kruess and Tscharntke 2002; Rada et al. 2014)

There is only limited information about the fauna of bracken-dominated stands. However, Pakeman and Marrs (1992) have pointed out that bracken can provide shelter for reptiles, birds and mammals and might therefore be of some importance for areas with lacking scrub, woodland or tall herbaceous vegetation. With regard to invertebrates, only very few species are known to directly depend on bracken or to use bracken stands as preferred (sub)habitats: In the UK, 40 species of arthropods have been observed to feed on bracken and 11 species are thought to be confined to this food plant (Lawton 1976). In Central Europe, 32 monophagous or oligophagous and 12 polyphagous insect species were found to feed on bracken (Wieczorek 1972), including some Hymenoptera, Diptera, Lepidoptera, Heteroptera and Homoptera. Bracken in south-facing lowland habitats has been considered essential to four highly threatened Fritillary butterflies in the UK (www.butterfly-conservation.org), including the High Brown Fritillary (Fabriciana [Argynnis] adippe), which has been observed to frequently lay its eggs in dead bracken and to complete pupation close to the ground under bracken (Ellis et al. 2019). But apart from these observations, dense bracken stands are generally assumed to be poor in animal species (Pakeman and Marrs 1992).

Our study aims to investigate the effect of bracken overgrowth in dry northern Alpine grassland on Orthoptera communities. To the best of our knowledge, this scenario has not been investigated yet in major conservation studies. Orthoptera are known to be sensitive to habitat management and environmental changes like grazing, mowing and grassland abandonment (Marini et al. 2009), which makes them appropriate indicators of succession processes and ecological alterations (Gerlach et al. 2013), including those in dry grasslands (Fartmann et al. 2012). Explicitly, we have addressed the following research questions:

(i) How does the intensity of bracken overgrowth affect orthopteran species richness and abundance in general and Red List Orthoptera in particular?

(ii) Do strata with low, medium or high bracken cover harbour distinct Orthoptera communities with a high species turnover (beta diversity)?

(iii) Which Orthoptera species are associated with strata or strata combinations with different levels of bracken cover?

\section{Methods}

\section{Study area}

The study area covers around 30 hectares and is part of a larger military training zone in eastern Switzerland near the city of Chur at the foot of the Alpine Calanda massif (N 46 51'35"; E 9 29'20"). It is situated along a steep, southeast-exposed slope between approximately 700 and $950 \mathrm{~m}$ a.s.l., which partly serves the army as a target area for shooting exercises. Most of the study area has been extensively or moderate-intensively grazed by sheep for decades. Since 2014 a rotational grazing system with four separate rotational paddocks has been established. In 2019, a total of 174 sheep were present within the study area for 106 consecutive days between mid-May and the end of August (pers. comm. M. Staub).

The vegetation mainly consists of dry (Xerobromion) and semi-dry (Mesobromion) grassland with scattered stony and rocky patches supplemented by subareas characterized by scrub encroachment and bracken infestation. The calcareous base rock is covered with a layer of brown earth (Waldvogel 1987). The study area has been protected by law since 2010 and is part of the Swiss inventory of dry meadows and dry pastures of national importance (object no. 8516). The habitat conditions for bracken, which prefers moist or alternating moist and acidic soils, are not favorable (Frei et al. 2019). Nonetheless, bracken has overgrown parts of the study area, mostly with sparse cover only, but on a few smaller subareas with medium to even high cover. Dry bracken can increase fire risk, particularly in military target areas, and this danger is enhanced by the warm foehn climate and low annual precipitation of slightly over $800 \mathrm{~mm}$ (Wohlgemuth and Wasem 2014). Burnt subareas are known to facilitate the establishment of new bracken by removal of its competitors (Page 1982).

\section{Sample plots}

Based on aerial photographs (Swisstopo 2019), a total of 24 sample plots with no woody plants or with only negligible scrub encroachment were randomly selected throughout the study area. The plot size was approximately 400 $\mathrm{m}^{2}$. We distinguished three strata, each consisting of eight plots characterized by different proportions of bracken cover: (1) "Bracken sparse" $<5 \%,(2)$ "Bracken medium" $10-30 \%$, and (3) "Bracken dense" $>50 \%$ (Fig. 1). The distance between each of the plots was generally more than $100 \mathrm{~m}$ in order to minimize edge effects and to obtain spatially independent results. In the case of four plots with dense bracken cover, only a minimal distance of around 


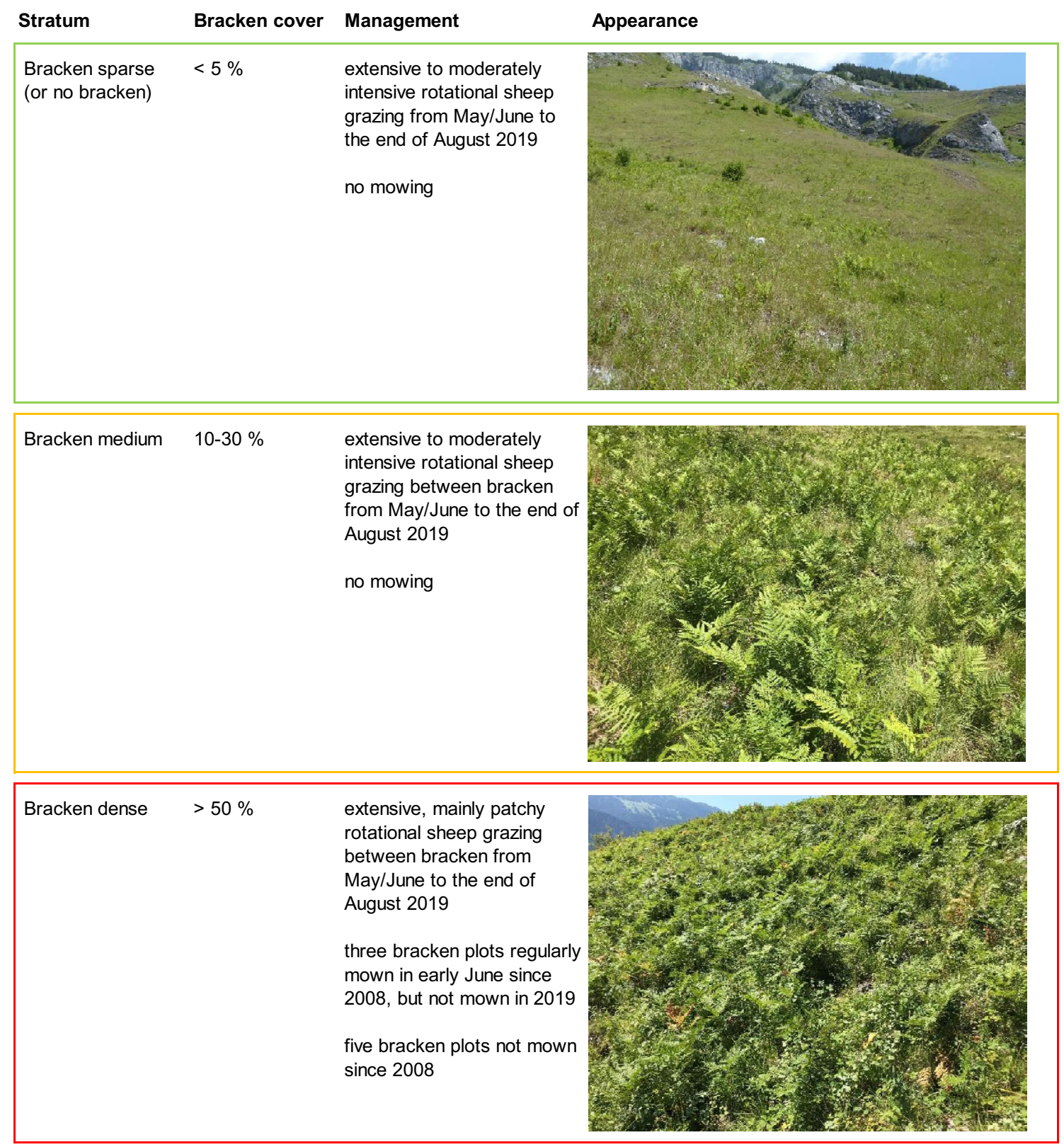

Fig. 1 Stratification of the sample plots according to their bracken fern (Pteridium aquilinum) cover, with specification of grazing and mowing management in 2019

$50 \mathrm{~m}$ could be maintained due to limited distribution of dense bracken stands in the study area. Three of the eight "Bracken dense" plots have been mown once a year in early June since 2008 (Frei et al. 2019), but not in 2019 to ensure comparable Orthoptera recordings. Mown and unmown "Bracken dense" plots neither differed in orthopteran species richness nor in mean average orthopteran species abundance (Mann-Whitney $U$ test, $P=1$ and $P=0.76)$ which allowed us to pool the data.

\section{Orthoptera sampling and nomenclature}

Each of the 24 sample plots was recorded twice between 1 and 31 August 2019 to assess the species composition and abundance of Orthoptera (suborders Ensifera and Caelifera). In August, the imagines of most Orthoptera in Switzerland show the highest abundances (Baur et al. 2006). The recordings were undertaken between 10:00 a.m. and 17:00 p.m. CEST on sunny days with temperatures above $20^{\circ} \mathrm{C}$. In the 
early afternoons, the valley wind increased regularly, but hardly impaired the field work due to the warm and sunny weather conditions in August 2019. Each plot was inspected over a period of 30 min per survey, applying a modified time counts method (Gardiner et al. 2005). All recordings were carried out by the authors, identifying species both by visual sighting and acoustic features. Additionally, we performed sweep netting, double-sweeping the vegetation three times back and forth in a $180^{\circ}$ arc in front of the observer at four randomly chosen points within each plot, resulting in a total of 12 once-and-back sweeps per plot and survey. After determination, all individuals were released. For the classification of the Orthoptera species we used five-grade ordinal abundance classes adapted to Kati et al. (2012): no individuals, 1-3 individuals, 4-10 individuals, $11-50$ individuals, and $>50$ individuals per plot and survey (Table 1 ). For further data analysis, we only used the higher of the two abundance classes recorded for each species during the two surveys. The nomenclature is according to the stera Platform (2020) (orthoptera.ch).

\section{Data analysis and statistics}

To assess the variation in orthopteran species richness between the strata "Bracken sparse", "Bracken medium" and "Bracken dense" we first performed an Analysis of variance (ANOVA), followed by post-hoc comparisons of strata means with paired $\mathrm{t}$ tests applying adjusted $P$ values with Holm correction. Preliminary tests proved normal distribution of our data set (Shapiro-Wilks test, $P>0.05$ ) and homogeneity of variances between the strata (Fligner-Killeen test and Levène test, both $P>0.05$ ). Collinearity between the predictor strata was checked using the Variance Inflation Factor (VIF). All predictor variables had VIF values below 2, indicating low collinearity (Zuur et al. 2009). We examined differences in overall orthopteran abundance with a Friedman rank sum test, comparing the cumulative numbers of abundance classes between the strata. Additionally, we performed separate Chi-square goodness of fit tests for each abundance class to assess the within-class variation of orthopteran abundance.

Table 1 Averaged abundance means and Ordinal Transfer Values (OTV) as ordinal substitutes for abundance class categories

\begin{tabular}{lll}
\hline Abundance class & $\begin{array}{l}\text { Averaged abundance } \\
\text { mean }\end{array}$ & $\begin{array}{l}\text { Ordinal transfer } \\
\text { value (OTV) }\end{array}$ \\
\hline no individuals & 0 & 0 \\
$1-3$ individuals & 2 & 1 \\
$4-10$ individuals & 7 & 2 \\
$11-50$ individuals & 30 & 4 \\
$>50$ individuals & 80 & 7 \\
\hline
\end{tabular}

We used Principal Coordinates Analysis (PCoA), also known as metric multidimensional scaling (Borcard et al. 2018) to compare the Orthoptera communities of our 24 sampling sites, applying Bray-Curtis dissimilarities as distance measures for the assessment of species communities (Leyer and Wesche 2007). In addition, we compared the findings of the PCoA with the output of the incidence based Sørensen index (Sørensen 1948), a widely used measure for comparing the beta diversity of two communities based on presence-absence data (Magurran 2004). Subsequently, a Redundancy Analysis (RDA) was applied to determine the direct influence of bracken cover at species level. RDA is considered a suitable constrained ordination method for the analysis of linear distributions with short gradients (Leyer and Wesche 2007). $P$ values for the constrained axes were obtained by carrying out partial permutation tests of significance (499 permutations). A preliminary Detrended Correspondence Analysis (DCA) was performed, revealing a maximal gradient length of 2.3 standard deviation (SD) units of species turnover. Gradients below 3 SD units indicate linear responses (Šmilauer and Lepš 2014). Prior to the ordinations, Orthoptera abundance data were square root transformed to improve normality. For PCoA and RDA we used the ordination software CANOCO 5.04 (ter Braak and Šmilauer 2018).

Further, we performed a non-parametric Permutational Multivariate Analysis of Variance (PERMANOVA), based on Bray-Curtis dissimilarities, to assess the significance of orthopteran community responses to varying bracken cover. Firstly, we checked the multivariate homogeneity of data variances without detecting significant differences in data dispersion among the strata. $P$ values and Pseudo-F-statistics were subsequently assessed by permutation of residuals under a reduced model (Anderson 2005) using data subsets for pairwise comparisons of the multivariate strata dissimilarities. For the PERMANOVA analyses, we applied the "betadisper" and "adonis2" functions of the "vegan" package (Oksanen et al. 2020) in R statistical language version 3.6.3 (R Core Team 2020).

The Indicator Value (IndVal) method, developed by Dufrêne and Legendre (1997), combines measures of site specificity (ecological preference) and fidelity (strength of species-site association) to identify species that are significantly related to a specific site or habitat type (Ienco et al. 2020). We used a multi-level extension of the original IndVal method, which allows for the discovery of indicator species of both individual site groups and combinations of site groups, as described in De Cáceres et al. (2010). Therefore, we applied the "multipatt" function of the "indicspecies" R package, with "IndVal.g" as association function (De Cáceres and Jansen 2020). The abundance class values were averaged to make them available for the ordinations and the IndVal calculations (Table 1). For 
comparison purposes, we also performed these calculations by using Ordinal Transfer Values (OTV), adapted to Fredley et al. (2019), instead of averaged abundance means.

Gomphocerus sibiricus and Nemobius sylvestris, both occurring only in one plot with one single individual each, were omitted from ordination analyses but were both considered for species richness and abundance (Tables 2 and $3)$.

Table 2 Pairwise comparison of beta diversity among bracken fern (Pteridium aquilinum) strata, expressed as incidence based Sørensen index and multivariate PERMANOVA

\begin{tabular}{llrl}
\hline Strata comparison (beta diversity) & Sørensen index & \multicolumn{2}{l}{ PERMANOVA } \\
\cline { 3 - 4 } & & Pseudo-F & $P$ \\
\hline Bracken sparse vs. Bracken dense & 0.31 & 18.44 & 0.001 \\
$\begin{array}{l}\text { Bracken sparse vs. Bracken } \\
\text { medium }\end{array}$ & 0.13 & 2.84 & 0.016 \\
$\begin{array}{l}\text { Bracken medium vs. Bracken } \\
\quad \text { dense }\end{array}$ & 0.17 & 8.11 & 0.003 \\
\hline
\end{tabular}

\section{Results}

\section{Effect of bracken cover on orthopteran species richness and abundance}

In total, we observed 23 Orthoptera species across the 24 sample plots (Table 3, details see Appendix Table 4). According to the Swiss Red List for grasshoppers and crickets, Bicolorana bicolor, Calliptamus italicus, Oedipoda germanica, and Psophus stridulus are classified as vulnerable (VU), and Chorthippus mollis, Decticus verrucivorus, Oedipoda caerulescens, Omocestus rufipes, and Platycleis albopunctata as near threatened (NT) (Monnerat et al. 2007).

Overall, the mean orthopteran species richness differed strongly between the strata (Fig. 2; ANOVA, F $=18.5$, $P<0.001)$. Pairwise comparisons revealed that "Bracken dense" plots had a highly significantly lower species richness than "Bracken sparse" and "Bracken medium" plots (post-hoc $t$ tests, $P_{a d j}<0.01$ and $P_{a d j}<0.0001$ ). "Bracken sparse" and "Bracken medium" plots, however, did not
Table 3 Orthoptera species listed according to their favorite bracken fern (Pteridium aquilinum) strata or strata combinations, based on multilevel Indicator Value analysis (IndVal), ranked by their $P$ values

\begin{tabular}{|c|c|c|c|c|c|}
\hline \multirow[t]{2}{*}{ Species } & \multirow[t]{2}{*}{$\begin{array}{l}\text { Ensifera (E) } \\
\text { Caelifera (C) }\end{array}$} & \multirow[t]{2}{*}{$\begin{array}{l}\text { Red List } \\
\mathrm{CH}\end{array}$} & \multicolumn{3}{|c|}{$\begin{array}{l}\text { Multi-level indicator value analysis (IndVal) } \\
\text { for averaged abundance means }\end{array}$} \\
\hline & & & Estimate & Stratum/Strata & $P$ \\
\hline Chorthippus mollis & $\mathrm{C}$ & NT & 0.73 & Bracken sparse & 0.049 \\
\hline Oedipoda germanica & $\mathrm{C}$ & $\mathbf{V U}$ & 0.61 & Bracken sparse & 0.089 \\
\hline Gomphocerus sibiricus & $\mathrm{C}$ & $\mathrm{LC}$ & 0.35 & Bracken sparse & 1 \\
\hline Stenobothrus lineatus & $\mathrm{C}$ & $\mathrm{LC}$ & 0.98 & Bracken sparse or medium & 0.001 \\
\hline Calliptamus italicus & $\mathrm{C}$ & $\mathbf{V U}$ & 0.97 & Bracken sparse or medium & 0.001 \\
\hline Oedipoda caerulescens & $\mathrm{C}$ & NT & 0.97 & Bracken sparse or medium & 0.001 \\
\hline Psophus stridulus & $\mathrm{C}$ & $\mathbf{V U}$ & 0.95 & Bracken sparse or medium & 0.002 \\
\hline Platycleis albopunctata & $\mathrm{E}$ & NT & 0.94 & Bracken sparse or medium & 0.014 \\
\hline Stauroderus scalaris & $\mathrm{C}$ & $\mathrm{LC}$ & 0.75 & Bracken sparse or medium & 0.048 \\
\hline Decticus verrucivorus & $\mathrm{E}$ & NT & 0.77 & Bracken sparse or medium & 0.069 \\
\hline Gryllus campestris & $\mathrm{E}$ & $\mathrm{LC}$ & 0.66 & Bracken sparse or medium & 0.124 \\
\hline Bicolorana bicolor & $\mathrm{E}$ & $\mathbf{V U}$ & 0.74 & Bracken sparse or medium & 0.338 \\
\hline Phaneroptera falcata & $\mathrm{E}$ & $\mathrm{LC}$ & 0.93 & Bracken medium or dense & 0.002 \\
\hline Euthystira brachyptera & $\mathrm{C}$ & $\mathrm{LC}$ & 0.96 & Bracken medium or dense & 0.012 \\
\hline Leptophyes punctatissima & $\mathrm{E}$ & $\mathrm{LC}$ & 0.85 & Bracken medium or dense & 0.084 \\
\hline Oecanthus pellucens & $\mathrm{E}$ & $\mathrm{LC}$ & 0.43 & Bracken medium or dense & 0.748 \\
\hline Pholidoptera griseoaptera & $\mathrm{E}$ & $\mathrm{LC}$ & 0.43 & Bracken medium or dense & 0.766 \\
\hline Tettigonia viridissima & $\mathrm{E}$ & $\mathrm{LC}$ & 0.74 & Bracken dense & 0.013 \\
\hline Nemobius sylvestris & $\mathrm{E}$ & $\mathrm{LC}$ & 0.35 & Bracken dense & 1 \\
\hline Chorthippus biguttulus & $\mathrm{C}$ & $\mathrm{LC}$ & 1.00 & no specification & NA \\
\hline Pseudochorthippus parallelus & $\mathrm{C}$ & $\mathrm{LC}$ & 0.96 & no specification & NA \\
\hline Gomphocerippus rufus & $\mathrm{C}$ & $\mathrm{LC}$ & 0.84 & no specification & NA \\
\hline Omocestus rufipes & $\mathrm{C}$ & NT & 0.82 & no specification & NA \\
\hline
\end{tabular}

Red List species for Switzerland (Monnerat et al. 2007) are written in bold 
Fig. 2 Orthopteran species richness related to bracken fern (Pteridium aquilinum) overgrowth. Median (bold line), interquartile range (box), minmax values (whisker or box margin), and outlier (point) are shown. The significance levels represent adjusted outcomes of pairwise post-hoc t tests. $\mathrm{n}=$ number of sample plots. $* * * * P<0.0001 ; * * P<0.01$

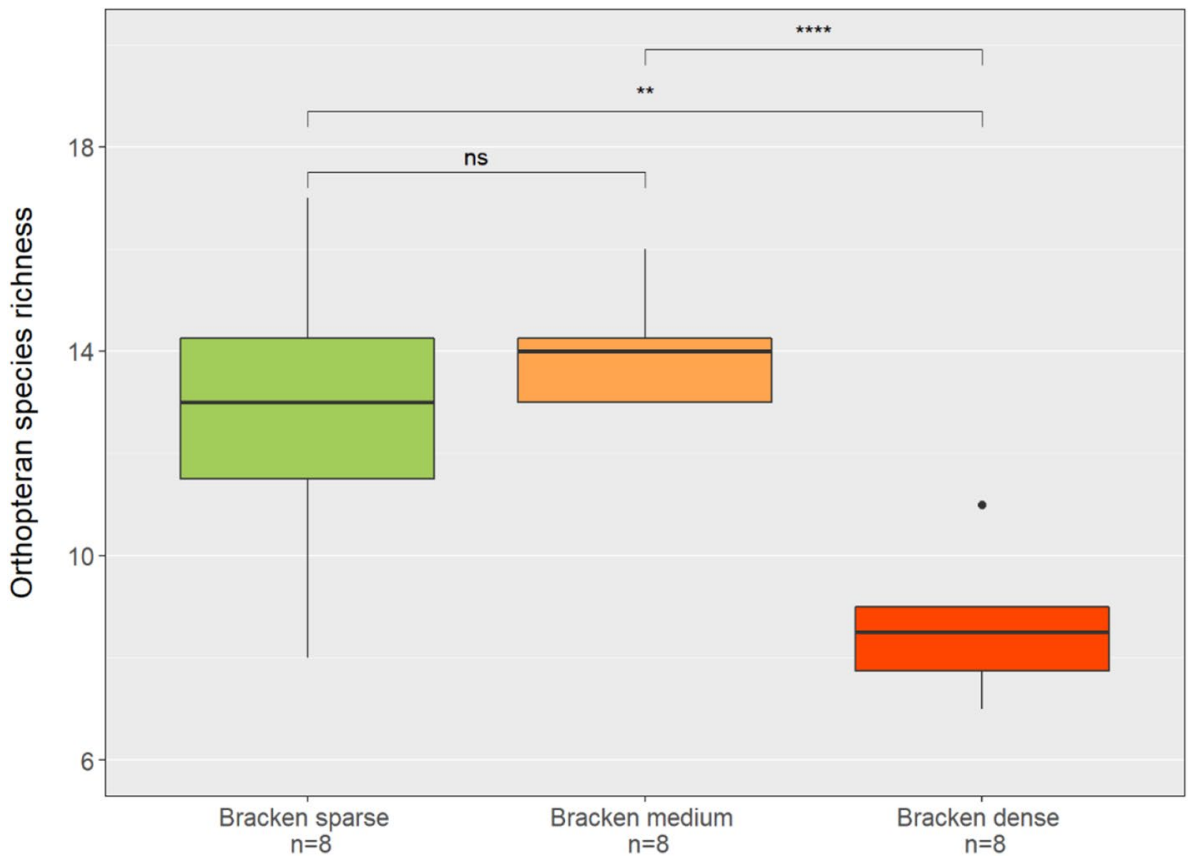

significantly differ in their species richness (post-hoc $t$ test, $P_{a d j}=0.27$ ).

There was no significant overall effect of bracken cover on orthopteran abundance (Friedmann rank sum test, $P=0.82$ ), due to only small across-strata data variance of the abundance classes "11-50 individuals" and " $>50$ individuals" (Chi-square goodness of fit test, $P=0.66$ and $P=0.48$ ). The non-significant overall outcome masks the significant across-strata differences of the lower abundance classes, which were mainly due to lower orthopteran presence in "Bracken dense" plots (allocation of abundance classes to strata see Appendix Table 4).

\section{Effect of bracken overgrowth on Orthoptera communities and their beta diversity}

The Principal Coordinate Analysis (PCoA) ordination plot in Fig. 3 reveals distinct patterns of strata clustering. The Orthoptera communities of the "Bracken dense" stratum differed notably from those of "Bracken medium" and "Bracken sparse". The latter two were more similar, though still indicating ecological gradients with unequal Orthoptera assemblages.

The outcomes of the Sørensen index confirm the findings of the PCoA, showing the highest compositional orthopteran
Fig. 3 Principal Coordinate Analysis PCoA, based on bracken fern (Pteridium aquilinum) overgrowth. The PCoA represents Bray-Curtis dissimilarities of orthopteran species' averaged abundance mean data

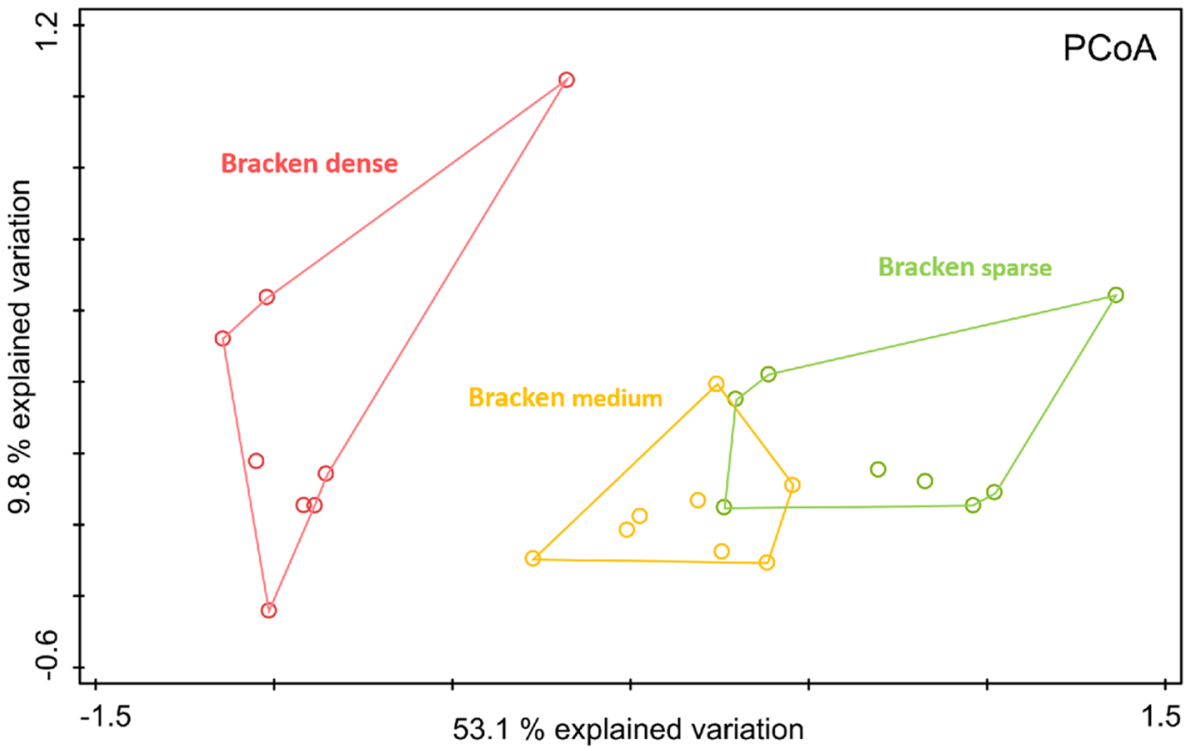


dissimilarities between the "Bracken dense" and "Bracken sparse" strata (0.31). In contrast, the dissimilarities between "Bracken dense" and "Bracken medium" (0.17) respectively "Bracken sparse" and "Bracken medium" (0.13) strata were much lower (Table 2). The high beta diversity between the strata was underlined by a Permutational Multivariate Analysis of Variance (PERMANOVA), yielding significant orthopteran dissimilarities between "Bracken sparse" and "Bracken medium" strata $(P=0.016)$. Even highly significant dissimilarities were found between "Bracken sparse" and "Bracken dense" $(P=0.001)$ and between "Bracken medium" and "Bracken dense" strata $(P=0.003)$.

\section{Orthoptera species associated with bracken overgrowth}

Indicator Value (IndVal) calculations, based on averaged abundance data, revealed that 13 of 24 Orthoptera species were significantly or marginally significantly associated with a single stratum or a combination of two strata (Table 3). Chorthippus mollis and Oedipoda germanica were found to be significantly or marginally significantly associated with "Bracken sparse" plots. Stenobothrus lineatus, Calliptamus italicus, Oedipoda caerulescens, Psophus stridulus, Platycleis albopunctata, and Stauroderus scalaris showed a highly significant or significant preference for the "Bracken sparse"/"Bracken medium" strata combination, and Decticus verrucivorus a marginally significant preference. Phaneroptera falcata and Euthystira brachyptera turned out to be significantly associated with the "Bracken medium"/"Bracken dense" strata combination, and Leptophyes punctatissima marginally significantly. Tettigonia viridissima proved to be the only species that was significantly associated with "Bracken dense" plots. Chorthippus biguttulus, Pseudochorthippus parallelus, Gomphocerippus rufus, and Omocestus rufipes were regularly found in all strata and had no specific preferences. Six out of seven species, which preferred "Bracken medium" or "Bracken medium"/"Bracken dense" strata belonged to the suborder Ensifera, though only two Ensifera species turned out to be significant. In contrast, species of the suborder Caelifera were mostly associated with "Bracken sparse" or "Bracken sparse"/"Bracken medium" strata, among those six significant species.

When running the IndVal analysis with Ordinal Transfer Values (OTV) instead of averaged abundance means, the output remained mostly consistent. The only substantial differences were detected for Euthystira brachyptera, Leptophyes punctatissima and Bicolorana bicolor, which didn't show specific strata preferences anymore $(P=\mathrm{NA})$.

The results of the IndVal analysis were validated by a Redundancy Analysis (RDA), illustrating constrained species-specific strata preferences (Fig. 4). Two separate groups can be distinguished: (1) Orthoptera species primarily populating low vegetation habitats with at most moderate bracken overgrowth, and (2) Orthoptera species mainly preferring habitats with dense or at least moderate bracken overgrowth, hardly occurring exclusively in low vegetation. All Red List species found were associated with low to medium bracken cover plots, mostly avoiding densely overgrown areas.
Fig. 4 Constrained ordination biplot based on a Redundancy Analysis (RDA) displaying Orthoptera communities according to their speciesspecific preference of bracken fern (Pteridium aquilinum). Partial test of axes with 499 permutations: 1st constrained axis $P=0.002,2$ nd constrained axis $P=0.17$ (with Pseudo-F 6.1 and 1.4)

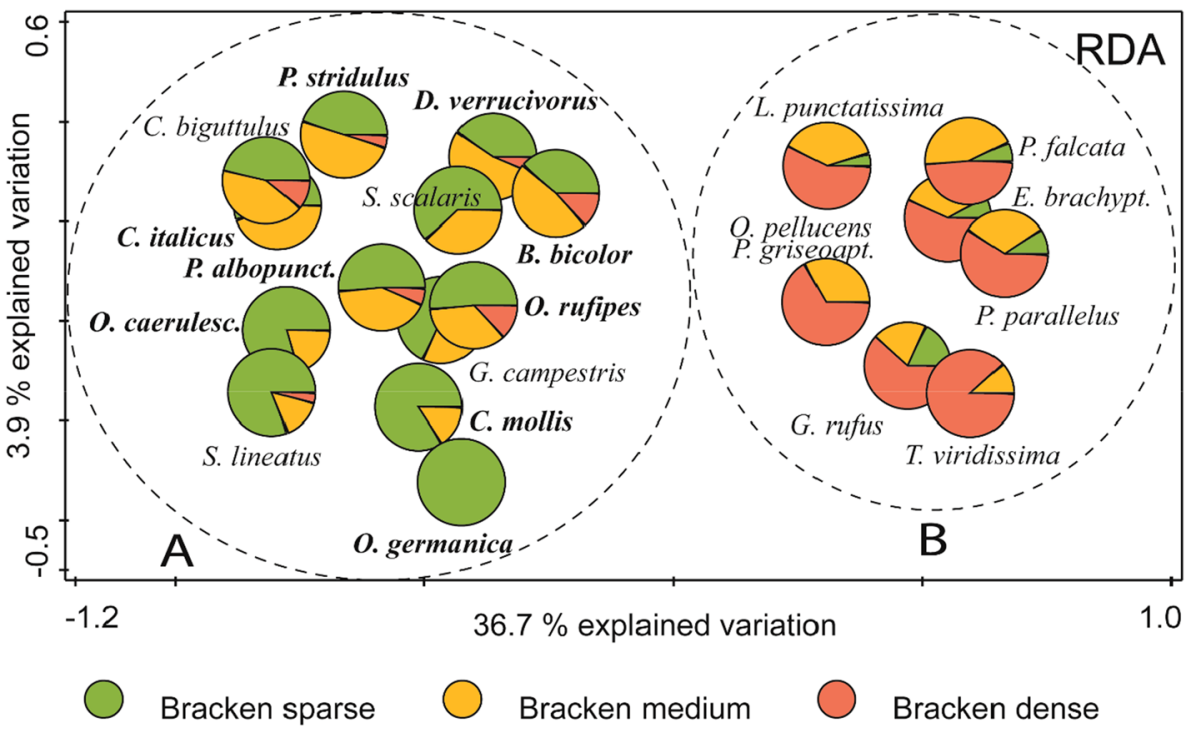




\section{Discussion}

\section{Effect of bracken cover on species richness and abundance}

Densely overgrown sample plots had a highly significant lower orthopteran species richness (median 8.5 species) than plots with only medium or sparse bracken cover (median 14 and 13 species respectively). A species richness peak in the mid-successional stages, as found to some extent in our study, is thought to reflect a trade-off between favorable ambient temperatures for optimal orthopteran development, sufficient food and shelter against predators (Fartmann et al. 2012).

The detrimental effect of bracken cover on species richness and biodiversity seems consistent with other studies, although most of them predominantly focused on floristic aspects. In the Italian Apennines, bracken strongly reduced the floristic richness of pastures (Argenti et al. 2012), and in Eastern Germany, regions with bracken cover had by far less plant species than adjacent meadows (Boronczyk 2005). Resulting nectar and pollen deficiencies and limited host plant availabilities are known to impair insect-flower interactions and insect diversity in general, e.g. with negative effects on wild bees (Goulson et al. 2015) or specialized butterfly species (Settele et al. 1999). In a small-scale preliminary study on butterflies in our study area, we found that the species richness on densely overgrown bracken plots was only about half as high as on plots with medium bracken cover or on subareas with low to medium scrub encroachment (Schlegel 2015, unpublished). After bracken control on Suffolk heathland (UK), most insect groups became more abundant, including Orthoptera species (S. J. Stevens pers. comm., cited in Pakeman and Marrs 1992). Apart from these, we are not aware of further systematic studies dealing with the effects of bracken on Orthoptera. The impact of scrub encroachment on species composition as a result of grassland abandonment, on the other hand, is far better investigated. From a faunistic point of view, especially with respect to Orthoptera, there are some similarities between the succession patterns, as ongoing scrub encroachment can lead to higher shading, more humid conditions and lower temperatures near the ground (Guido and Gianelle 2001). Such unfavorable conditions can harm above-ground stages of orthopteran life cycles (Willott and Hassall 1998). Many investigations, mainly in mountainous regions of Europe, have demonstrated a negative response of animal species richness by progressing scrub encroachment (e.g. MacDonald et al. 2000; Russo 2007). Studies on butterflies yielded an increasing diversity at the beginning of succession, which ultimately decreased in later stages (e.g. Stefanescu et al. 2009). Similar behavior was found with Ensifera species in north-eastern Italian meadows (Marini et al. 2010). Shading-out is thought to be less harmful to Ensifera as many of them oviposit in plants and therefore are less negatively affected by shading than most Caelifera which tend to oviposit in the soil (Ingrisch and Köhler 1998; Bieringer and Zulka 2003). Accordingly, most Ensifera found in our study area were characteristic to medium and densely overgrown sample plots, whereas most Caelifera were found in sparsely to medium overgrown plots.

\section{Effect of bracken cover on Orthoptera communities and beta diversity}

Performing unconstrained (Principal Coordinate Analysis PCoA) and constrained (Redundancy Analysis RDA) gradient analyses, we could illustrate that Orthoptera communities of the strata "Bracken sparse", "Bracken medium" and "Bracken dense" differed significantly in their species composition and abundance. Still, "Bracken medium" and "Bracken sparse" plots had more in common than strata combinations with "Bracken dense" plots. Nonetheless, plots with dense bracken cover contributed to the overall beta diversity in our study area, as they proved to be an exclusive or a preferred habitat for several Orthoptera species (for details see below Orthoptera species associated with bracken overgrowth). Walcher et al. (2017) observed distinct species compositions between meadows with low vegetation and abandoned meadows with high vegetation on Alpine mountain grasslands, pointing out in accordance with our findings, that low and sparse vegetation is particularly important for the conservation of endangered Orthoptera. Fartmann et al. (2012), who also conducted their research on dry grassland, claim a strong orthopteran response to succession, with each successional stage harboring a unique assemblage, indicating high beta diversity along the successional gradient. 


\section{Orthoptera species associated with bracken overgrowth}

The thermo- and xerophilous Red List species Chorthippus mollis and Oedipoda germanica both turned out to be significantly and marginally significantly associated with plots with sparse bracken overgrowth, whereas the eurytopic species Tettigonia viridissima proved to be the only characteristic species for plots with dense bracken overgrowth. North of the Alps, C. mollis generally prefers dry and warm conditions. $O$. germanica is even more restricted to the most arid, usually south-facing and stony slopes with only sparse vegetation (Detzel 1998), benefiting from goat or donkey grazing (Dipner et al. 2016; Hiller et al. 2020). $T$. viridissima is known to require well-structured habitats with a minimal share of shrubs and dense vegetation (Baur et al. 2006). Our Indicator Value (IndVal) analyses revealed, however, that the majority of the species were not only restricted to one single bracken stratum: nine species were characteristic for plots with sparse or medium bracken cover, six of them significant, including the Red List species Calliptamus italicus, Oedipoda caerulescens, Psophus stridulus, and Platycleis albopunctata. All Red List species mentioned generally favor sunny and dry locations with open soil and only sparse or patchy vegetation (Baur et al. 2006), though especially male $P$. stridulus are known to require at least partly dense vegetation (Hemp and Hemp 2003). The abundance of Gryllus campestris has been most likely underestimated, since our surveys took place in August and the reproductive season of this univoltine species, associated with higher activity on the ground surface, is mainly in May and June (Klaiber et al. 2017). During our survey we only found nymphs of G. campestris. We assume that this species, which prefers dry and sunny locations with short vegetation (Detzel 1998), would also have been associated with plots with sparse or medium bracken overgrowth if imagines had been included. Five species, but none of the Red List, were characteristic for plots with medium or dense bracken cover. All Red List Orthoptera species found were mostly restricted to sparse or medium bracken cover, which emphasizes the high conservation value of southerly exposed rocky slopes with only low vegetation and a high share of bare ground in our study area. In turn, Pholidoptera griseoaptera and Phaneroptera falcata turned out to be the only species associated with plots with medium to dense bracken cover, the latter of which yielded significant interactions. As mentioned, there is still very little known about Orthoptera communities of bracken-dominated stands. Overall, only very few Orthoptera species have been reported, such as the generalists Gomphocerippus rufus and Pholidoptera griseoaptera in bracken on extensively grazed pastures in Austria (AVL 2004), the latter of which have also been observed in bracken-infested forest clearings in Switzerland (pers. observations). Phaneroptera falcata was found in bracken in the proximity of our study area (Nadig and Steinmann 1972).

\section{Management implications}

As conservation efforts should generally focus on the creation of heterogeneity, explicitly on calcareous grasslands (Diacon-Bolli et al. 2012), rotational grazing is regarded as the most preferable and, with respect to the steep and partly inaccessible study area, the best applicable management system. Therefore, ongoing rotational sheep grazing system with temporary paddocks, as established in 2014, is believed to be the most appropriate approach for the preservation of specialized dry and semi-dry grassland animal target species, including Red List Orthoptera. A mosaic of extensively grazed grassland, and grassland left ungrazed for a few years, allows for the coexistence of different successional stages with mixed patterns of low-sparse and high-dense vegetation, which is likely to favor biodiversity and strengthen trophic interactions (Kruess and Tscharntke 2002). Transitional stages with patches of higher vegetation, as mainly found in ungrazed or undergrazed subareas in the lower parts of our study area, have repeatedly been reported to be suitable habitats for several Ensifera species (e.g. Marini et al. 2009; Schirmel et al. 2011). Such transitional stages, especially when affected by limited scrub encroachment, are also vital for the critically endangered species Saga pedo (Pallas 1771), one of the rarest Orthoptera species in Switzerland (Monnerat et al. 2007). A few individuals of $S$. pedo have been found in more densely vegetated parts of the lower study area over the past few years (pers. comm. P. Weidmann and S. Widmer; own observations). Due to overgrazing in some upper parts of the study area in 2019, we recommend excluding sections with only sparse vegetation and with no risk of bracken overgrowth or scrub encroachment alternately from grazing for some years, provided that it does not unduly increase fire risk during military shooting practice. 
Although bracken provides suitable additional habitat structures for some Orthoptera species, its expansion should be restricted to prevent further infestation, as most Orthoptera depend on high ambient temperatures (Willott and Hassall 1998), and Caelifera diversity is believed to decline with increasing vegetation cover (Walcher et al. 2017) and sward height (Gardiner et al. 2002). Thus, maintaining or even partly intensifying sheep grazing in the more vigorous parts of the lower study area is suggested, particularly in subareas with medium bracken cover and in the close surroundings of dense bracken stands. Additional conservation measures with low-intensity bracken control are also considered appropriate and should be pursued: A field experiment within the study area evaluated the impact of bracken control between 2008 and 2017, either by uprooting and removing the plants, or by mowing without removing the mulched vegetation (Frei et al. 2019). After eight years, the aboveground biomass of bracken on experimental sites was four times (mowing) to ten times (uprooting) smaller compared to the adjacent control plots. On the treatment plots, the number of vascular plant species per $\mathrm{m}^{2}$ was significantly higher than on the control plots (Widmer et al. 2018).

Along with additional Orthoptera species found in the military training zone, 31 species have been recorded so far, among those the endangered species Myrmeleotettix maculatus (Thunberg 1815), detected in 2016 for the first time after more than 80 years in eastern Switzerland's lowlands (Schlegel and Riesen 2018). Taken as a whole, the military training zone, primarily our study area, can be regarded as one of the most outstanding Orthoptera sites north of the Swiss Alps. The current management system, combined with the minor adjustments mentioned, is believed to be adequate not only for the conservation of the current Orthoptera diversity, with many Red List species included, but also for the protection of numerous other species of northern Alpine dry grasslands.

\section{Appendix}

See Table 4.

Table 4 Species-specific orthopteran abundance classes depending on bracken fern (Pteridium aquilinum) overgrowth

\begin{tabular}{|c|c|c|c|c|c|c|c|c|c|c|c|c|c|c|c|}
\hline \multirow[t]{3}{*}{ Orthopteran abundance (individuals) } & \multicolumn{15}{|c|}{ Number of plots containing the respective orthopteran abundance classes } \\
\hline & \multicolumn{5}{|c|}{ Bracken sparse $(n=8)$} & \multicolumn{5}{|c|}{ Bracken medium $(\mathrm{n}=8)$} & \multicolumn{5}{|c|}{ Bracken dense $(n=8)$} \\
\hline & 0 & $1-3$ & $4-10$ & $11-50$ & $>50$ & 0 & $1-3$ & $4-10$ & $11-50$ & $>50$ & 0 & $1-3$ & $4-10$ & $11-50$ & $>50$ \\
\hline Bicolorana bicolor & 4 & 2 & 2 & 0 & 0 & 2 & 4 & 2 & 0 & 0 & 5 & 3 & 0 & 0 & 0 \\
\hline Calliptamus italicus & 0 & 1 & 4 & 3 & 0 & 1 & 0 & 5 & 2 & 0 & 8 & 0 & 0 & 0 & 0 \\
\hline Chorthippus biguttulus & 0 & 0 & 0 & 0 & 8 & 0 & 0 & 0 & 1 & 7 & 0 & 0 & 4 & 4 & 0 \\
\hline Chorthippus mollis & 3 & 2 & 2 & 1 & 0 & 6 & 1 & 1 & 0 & 0 & 8 & 0 & 0 & 0 & 0 \\
\hline Decticus verrucivorus & 4 & 3 & 1 & 0 & 0 & 2 & 5 & 1 & 0 & 0 & 7 & 1 & 0 & 0 & 0 \\
\hline Euthystira brachyptera & 2 & 2 & 3 & 1 & 0 & 0 & 1 & 3 & 2 & 2 & 0 & 1 & 1 & 2 & 4 \\
\hline Gomphocerippus rufus & 4 & 1 & 0 & 3 & 0 & 2 & 2 & 1 & 3 & 0 & 1 & 0 & 0 & 5 & 2 \\
\hline Gomphocerus sibiricus & 7 & 1 & 0 & 0 & 0 & 8 & 0 & 0 & 0 & 0 & 8 & 0 & 0 & 0 & 0 \\
\hline Gryllus campestris & 4 & 3 & 1 & 0 & 0 & 5 & 3 & 0 & 0 & 0 & 8 & 0 & 0 & 0 & 0 \\
\hline Leptophyes punctatissima & 4 & 4 & 0 & 0 & 0 & 1 & 2 & 4 & 1 & 0 & 3 & 2 & 0 & 3 & 0 \\
\hline Nemobius sylvestris & 8 & 0 & 0 & 0 & 0 & 8 & 0 & 0 & 0 & 0 & 7 & 1 & 0 & 0 & 0 \\
\hline Oecanthus pellucens & 8 & 0 & 0 & 0 & 0 & 7 & 1 & 0 & 0 & 0 & 6 & 2 & 0 & 0 & 0 \\
\hline Oedipoda caerulescens & 0 & 2 & 1 & 2 & 3 & 1 & 3 & 2 & 2 & 0 & 8 & 0 & 0 & 0 & 0 \\
\hline Oedipoda germanica & 5 & 3 & 0 & 0 & 0 & 8 & 0 & 0 & 0 & 0 & 8 & 0 & 0 & 0 & 0 \\
\hline Omocestus rufipes & 2 & 2 & 4 & 0 & 0 & 2 & 4 & 2 & 0 & 0 & 4 & 4 & 0 & 0 & 0 \\
\hline Phaneroptera falcata & 5 & 2 & 1 & 0 & 0 & 1 & 1 & 5 & 1 & 0 & 0 & 1 & 6 & 1 & 0 \\
\hline Pholidoptera griseoaptera & 8 & 0 & 0 & 0 & 0 & 7 & 1 & 0 & 0 & 0 & 6 & 2 & 0 & 0 & 0 \\
\hline Platycleis albopunctata & 0 & 3 & 4 & 1 & 0 & 1 & 4 & 2 & 1 & 0 & 4 & 4 & 0 & 0 & 0 \\
\hline Pseudochorthippus parallelus & 2 & 3 & 3 & 0 & 0 & 0 & 2 & 4 & 2 & 0 & 0 & 0 & 3 & 5 & 0 \\
\hline Psophus stridulus & 1 & 6 & 1 & 0 & 0 & 0 & 7 & 1 & 0 & 0 & 7 & 1 & 0 & 0 & 0 \\
\hline Stauroderus scalaris & 4 & 2 & 1 & 1 & 0 & 3 & 2 & 3 & 0 & 0 & 8 & 0 & 0 & 0 & 0 \\
\hline Stenobothrus lineatus & 0 & 1 & 3 & 4 & 0 & 0 & 6 & 2 & 0 & 0 & 7 & 0 & 1 & 0 & 0 \\
\hline Tettigonia viridissima & 8 & 0 & 0 & 0 & 0 & 7 & 1 & 0 & 0 & 0 & 3 & 4 & 1 & 0 & 0 \\
\hline
\end{tabular}


Acknowledgements This study was funded by the Swiss Federal Department of Defense, Civil Protection and Sport (VBS). We mainly thank Dr. David Külling, VBS, for the support and cooperation. The writing of the publication has been supported by Martec Handels AG, Wollerau. Many thanks are also due to Jason Parry for the English language check. Adrian Hochreutener helped with proofreading. Markus Staub provided us with background information about sheep grazing in the study area. We would also like to thank two anonymous reviewers for their helpful inputs on an earlier version of the manuscript.

Funding Open Access funding provided by ZHAW Zürcher Hochschule für Angewandte Wissenschaften.

\section{Declarations}

Conflict of interest The authors declare that they have no competing financial interests or personal relationships that could have appeared to influence the work reported in this paper. All sources of funding are acknowledged in the manuscript.

Ethical approval The work is all original research carried out by the authors. The authors agree with the contents of the manuscript and its submission to the journal. No part of the research has been published in any form elsewhere. This study is not split up into several parts to increase the quantity of submissions. The manuscript is not being considered for publication elsewhere while it is being considered for publication in this journal. No data, text, or theories by others are presented as if they were the author's own. Proper acknowledgements to other works are given in the text and references. The results are presented honestly and without fabrication, falsification or inappropriate data manipulation.

Human rights and participants No human beings were involved as participants in our study. Our research focused exclusively on invertebrates (Orthoptera), which were sweep-netted, determined and then released again.

Open Access This article is licensed under a Creative Commons Attribution 4.0 International License, which permits use, sharing, adaptation, distribution and reproduction in any medium or format, as long as you give appropriate credit to the original author(s) and the source, provide a link to the Creative Commons licence, and indicate if changes were made. The images or other third party material in this article are included in the article's Creative Commons licence, unless indicated otherwise in a credit line to the material. If material is not included in the article's Creative Commons licence and your intended use is not permitted by statutory regulation or exceeds the permitted use, you will need to obtain permission directly from the copyright holder. To view a copy of this licence, visit http://creativecommons.org/licenses/by/4.0/.

\section{References}

Anderson MJ (2005) Permutational multivariate analysis of variance. Department of statistics. Univ Auckland Auckland 26:32-46

Arbeitsgemeinschaft Vegetationsökologie Landschaftsplanung AVL (2004) Tierökologisches Monitoring der Magerweiden am Sonnberg in Laussa. Endbericht des Monitoringprogramms 1993-2002

Argenti, G., Cervasio, F., Ponzetta, M.P. (2012) Control of bracken (Pteridium aquilinum) and feeding preferences in pastures grazed by wild ungulates in an area of the Northern Apennines (Italy). Italian Journal of Animal Science 11:e62
Baur B, Baur H, Roesti C, Roesti D (2006) Die Heuschrecken der Schweiz. Haupt, Bern

Bieringer G, Zulka KP (2003) Shading out species richness: edge effect of a pine plantation on the Orthoptera (Tettigoniidae and Acrididae) assemblage of an adjacent dry grassland. Biodivers Conserv 12:1481-1495. https://doi.org/10.1023/A:10236 33911828

Birch CP, Vuichard N, Werkman BR (2000) Modelling the effects of patch size on vegetation dynamics: Bracken [Pteridium aquilinum (L.) Kuhn] under grazing. Ann Bot-London 85:63-76

Borcard, D., Gillet, F., Legendre, P. (2018) Numerical ecology with R. Springer International, Basel

Boronczyk M (2005) Problempflanze Adlerfarn: Die Auswirkungen auf die Artenvielfalt und verschiedene Strategien zur Bekämpfung. Pulsatilla 8:33-39

De Cáceres M, Jansen F (2020) Indicspecies: relationship between species and groups of sites. R Package Version 1(7):9

De Cáceres M, Legendre P, Moretti M (2010) Improving indicator species analysis by combining groups of sites. Oikos 119:1674-1684

Der JP, Thomson JA, Stratford JK, Wolf PG (2009) Global chloroplast phylogeny and biogeography of bracken (Pteridium; Dennstaedtiaceae). Am J Bot 96:1041-1049. https://doi.org/10.3732/ajb. 0800333

Detzel P (1998) Die Heuschrecken Baden-Württembergs. Ulmer, Stuttgart

Diacon-Bolli J, Dalang T, Holderegger R, Bürgi M (2012) Heterogeneity fosters biodiversity: linking history and ecology of dry calcareous grasslands. Basic Appl Ecol 13:641-653

Dipner, M., Durrer, S., Jöhl, R. (2016) Allegra Geissenpeter: Leitfaden für die Aufwertung von brachliegenden Trockenstandorten durch Beweidung. Pro Natura, Basel

Dolling A, Zackrisson O, Nilsson MC (1994) Seasonal variation in phytotoxicity of bracken (Pteridium aquilinum L. Kuhn). J Chem Ecol 20:3163-3172

Dufrêne M, Legendre P (1997) Species assemblages and indicator species: the need for a flexible asymmetrical approach. Ecol Monogr 67:345-366

Ellis S, Wainwright D, Dennis E, Bourn N, Bulman C, Hobson R, Jones R, Middlebrook I, Plackett J, Smith R (2019) Are habitat changes driving the decline of the UK's most threatened butterfly: the High Brown Fritillary Argynnis adippe (Lepidoptera: Nymphalidae)? J Insect Conserv 23:351-367

Fartmann T, Krämer B, Stelzner F, Poniatowski D (2012) Orthoptera as ecological indicators for succession in steppe grassland. Ecol Indic 20:337-344

Fredley J, Durako MJ, Hall MO (2019) Multivariate analyses link macrophyte and water quality indicators to seagrass die-off in Florida Bay. Ecol Indic 101:692-701

Frei ES, Widmer S, Babbi M, Krüsi B (2019) Extensive Bekämpfung des Adlerfarns an einem voralpinen Trockenstandort. Naturschutz Und Landschaftsplanung 51:374-381

Gardiner T, Pye M, Field R, Hill J (2002) The influence of sward height and vegetation composition in determining the habitat preferences of three Chorthippus species (Orthoptera: Acrididae) in Chelmsford, Essex, UK. J Orthoptera Res 11:207-213

Gardiner T, Hill J, Chesmore D (2005) Review of the methods frequently used to estimate the abundance of Orthoptera in grassland ecosystems. J Insect Conserv 9:151-173

Gerlach J, Samways M, Pryke J (2013) Terrestrial invertebrates as bioindicators: an overview of available taxonomic groups. J Insect Conserv 17:831-850. https://doi.org/10.1007/s10841-013-9565-9

Gliessman SR (1976) Allelopathy in a broad spectrum of environments as illustrated by bracken. Bot J Linn Soc 73:95-104

Goulson D, Nicholls E, Botías C, Rotheray EL (2015) Bee declines driven by combined stress from parasites, pesticides, and lack of flowers. Science. https://doi.org/10.1126/science.1255957 
Guido M, Gianelle D (2001) Distribution patterns of four Orthoptera species in relation to microhabitat heterogeneity in an ecotonal area. Acta Oecol 22:175-185

Hemp C, Hemp A (2003) Lebensraumansprüche und Verbreitung von Psophus stridulus (Orthoptera: Acrididae) in der Nördlichen Frankenalb. Articulata 18:51-70

Hiller G, Elias D, Köhler M, Tischew S (2020) Förderung der Rotflügligen Ödlandschrecke (Oedipoda germanica). Ziegenrotationsbeweidung auf verbuschten Kalktrockenrasen. Naturschutz Und Landschaftsplanung 52:518-523

Hunter MD, Price PW (1992) Playing chutes and ladders: heterogeneity and the relative roles of bottom-up and top-down forces in natural communities. Ecology 73:724-732

Ienco A, Greco S, Scalercio S (2020) Is the "best season" the best choice? Temporal variations of $\beta$-diversity patterns in moth communities of Calabrian black pine forests. Ecol Indic 112:106134

Ingrisch, S., Köhler, G. (1998) Die Heuschrecken Europas. WestarpWissenschaften, Hohenwarsleben

Kati V, Zografou K, Tzirkalli E, Chitos T, Willemse L (2012) Butterfly and grasshopper diversity patterns in humid Mediterranean grasslands: the roles of disturbance and environmental factors. J Insect Conserv 16:807-818. https://doi.org/10.1007/s10841-012-9467-2

Klaiber J, Altermatt F, Birrer S, Chittaro Y, Dziock F, Gonseth Y, Hoess R, Keller D, Küchler H, Luka H, Manzke U, Müller A, Pfeifer MA, Roesti C, Schlegel J, Schneider K, Sonderegger P, Walter T, Holderegger R, Bergamini A (2017) Fauna Indicativa. WSL Berichte 54

Kruess A, Tscharntke T (2002) Grazing intensity and the diversity of grasshoppers, butterflies, and trap-nesting bees and wasps. Conserv Biol 16:1570-1580

Lawton J (1976) The structure of the arthropod community on bracken. Bot J Linn Soc 73:187-216

Lawton JH, Schroder D (1977) Effects of plant type, size of geographical range and taxonomic isolation on number of insect species associated with British plants. Nature 265:137-140. https://doi.org/10.1038/265137a0

Leyer I, Wesche K (2007) Multivariate Statistik in der Ökologie: Eine Einführung. Springer, Heidelberg

MacDonald D, Crabtree JR, Wiesinger G, Dax T, Stamou N, Fleury P, Lazpita JG, Gibon A (2000) Agricultural abandonment in mountain areas of Europe: environmental consequences and policy response. J Environ Manage 59:47-69

Magurran AE (2004) Measuring biological diversity. Blackwell, Oxford

Marini L, Fontana P, Battisti A, Gaston KJ (2009) Response of orthopteran diversity to abandonment of semi-natural meadows. Agr Ecosyst Environ 132:232-236. https://doi.org/10.1016/j. agee.2009.04.003

Marini L, Bommarco R, Fontana P, Battisti A (2010) Disentangling effects of habitat diversity and area on orthopteran species with contrasting mobility. Biol Conserv 143:2164-2171. https://doi. org/10.1016/j.biocon.2010.05.029

Marrs RH, Watt AS (2006) Biological Flora of the British Isles: Pteridium aquilinum (L.) Kuhn. J Ecol 94:1272-1321. https://doi.org/ 10.1111/j.1365-2745.2006.01177.x

Marrs R, Pakeman R, Lowday J (1995) Bracken control and heathland restoration in Breckland. In: Bracken: An Environmental Issue. International Bracken Group, Special Publication No. 2. University of Wales, Aberystwyth, pp 166-172

Monnerat C, Thorens P, Walter T, Gonseth Y (2007) Rote Liste Heuschrecken. Umwelt-Vollzug 0719. BAFU/CSCF, Bern/Neuchâtel

Nadig A, Steinmann E (1972) Orthopteren (Geradflügler) und Apoiden (Bienen) am Fusse des Calanda im Churer Rheintal. Jahresbericht Der Naturforschenden Gesellschaft Graubünden 95:3-88
Oksanen J, Blanchet F, Friendly M, Kindt R, Legendre P, Mcglinn D, Stevens M (2020) Package_-vegan: Community Ecology package. $\mathrm{R}$ package version $2.5-6$

Orthoptera.ch [Swiss Orthoptera Forum] (2020). https://www.ortho ptera.ch. Accessed 21 Dec 2020

Page CN (1982) The history and spread of bracken in Britain. P Roy Soc Edinb B 81:3-10. https://doi.org/10.1017/S02697270000032 01

Pakeman RJ, Marrs RH (1992) The conservation value of bracken Pteridium aquilinum (L.) Kuhn-dominated communities in the UK, and an assessment of the ecological impact of bracken expansion or its removal. Biol Conserv 62:101-114. https://doi.org/10. 1016/0006-3207(92)90931-C

Pakeman RJ, Le Duc MG, Marrs R (2002) A review of current bracken control and associated vegetation strategies in Great Britain. Web Ecol 3:6-11

R Core Team (2020) R: A Language and Environment for Statistical Computing (version 3.6.3). R Foundation for Statistical Computing, Vienna, Austria. https://www.R-project.org/

Rada S, Mazalová M, Šipoš J, Kuras T (2014) Impacts of mowing, grazing and edge effect on orthoptera of submontane grasslands: perspectives for biodiversity protection. Pol J Ecol 62:123-138. https://doi.org/10.3161/104.062.0112

Russo D (2007) Effects of land abandonment on animal species in Europe: conservation and management implications. Integrated assessment of vulnerable ecosystems under global change in the European Union. Project report. European Commission, Community Research, Sustainable development, global change and ecosystems, pp 1-51

Schirmel J, Mantilla-Contreras J, Blindow I, Fartmann T (2011) Impacts of succession and grass encroachment on heathland Orthoptera. J Insect Conserv 15:633-642. https://doi.org/10.1007/ s10841-010-9362-7

Schlegel J, Riesen M (2018) Lebensraum Waffenplatz: Wiederfund der Gefleckten Keulenschrecke Myrmeleotettix maculatus (Thunberg, 1815) (Orthoptera: Acrididae) im Talraum der Ostschweiz nach über 80 Jahren. Entomo Helvetica 11:17-24

Settele J, Feldmann R, Reinhardt R (1999) Die Tagfalter Deutschlands. Ulmer, Stuttgart

Šmilauer P, Lepš J (2014) Multivariate analysis of ecological data using CANOCO 5. Cambridge University Press

Sørensen TA (1948) A method of establishing groups of equal amplitude in plant sociology based on similarity of species content and its application to analyses of the vegetation on Danish commons. Kong Dansk Vidensk 5:1-34

Stefanescu C, Peñuelas J, Filella I (2009) Rapid changes in butterfly communities following the abandonment of grasslands: a case study. Insect Conserv Diver 2:261-269. https://doi.org/10.1111/j. 1752-4598.2009.00063.x

Swisstopo (2019) [Swiss Federal Office of Topography]. https://map. geo.admin.ch

Ter Braak CJF, Šmilauer P (2018) Canoco Software for Ordination, version 5.10. Microcomputer Power, USA

Thomson JA, Smith RT (1990) Bracken biology and management. Occasional Publication, Australian Institute of Agricultural Science, $\mathrm{p} 40$

Walcher R, Karrer J, Sachslehner L, Bohner A, Pachinger B, Brandl D, Zaller JG, Arnberger A, Frank T (2017) Diversity of bumblebees, heteropteran bugs and grasshoppers maintained by both: abandonment and extensive management of mountain meadows in three regions across the Austrian and Swiss Alps. Landscape Ecol 32:1937-1951

Waldvogel D (1987) Naturkundliche Beobachtungen auf dem Schiessplatz Rheinsand bei Chur. Jahresbericht Der Naturforschenden Gesellschaft Graubünden 104:55-109 
Widmer S, Frei ES, Babbi M, Krüsi BO (2018) Extensive Bekämpfung des Adlerfarns fördert die floristische Vielfalt. Bauhinia 27:33-41

Wieczorek H (1972) Zur Kenntnis der Adlerfarninsekten Ein Beitrag zum Problem der biologischen Bekämpfung von Pteridium aquilinum (L.) Kuhn in Mitteleuropa. Z Angew Entomol 72:337-358

Willott S, Hassall M (1998) Life-history responses of British grasshoppers (Orthoptera: Acrididae) to temperature change. Funct Ecol 12:232-241

Wohlgemuth T, Wasem U (2014) Klimaentwicklung im Churer Rheintal von 1888 bis 2013. Bündner Wald 6:13-16
Zuur A, Ieno EN, Walker N, Saveliev AA, Smith GM (2009) Mixed effects models and extensions in ecology with R. Springer Science + Business Media, New York

Publisher's Note Springer Nature remains neutral with regard to jurisdictional claims in published maps and institutional affiliations. 